\title{
Parasites of domestic and Wild animals in South Africa. XLVIII. TICKS (ACARI: IXODIDAE) INFESTING DOMESTIC CATS AND WILD FELIDS IN SOUTHERN AFRICA
}

\section{Authors:}

Ivan G. Horak ${ }^{1,2}$

Heloise Heyne $^{3}$

Edward F. Donkin ${ }^{4}$

Affiliations:

${ }^{1}$ Department of Veterinary

Tropical Diseases,

University of Pretoria,

South Africa

${ }^{2}$ Department of Zoology

and Entomology,

University of the Free State,

South Africa

${ }^{3}$ ARC-Onderstepoort

Veterinary Institute,

Onderstepoort,

South Africa

${ }^{4}$ Department of Production Animal Studies, University of Pretoria, South Africa

\section{Correspondence to:}

Ivan Horak

email:

ivan.horak@up.ac.za

\section{Postal address:}

Faculty of Veterinary

Science, Private Bag X04,

Onderstepoort 0110,

South Africa

\section{Keywords:}

domestic cats; ixodid ticks; 19 species; southern Africa; wild felids

\section{Dates:}

Received: 19 April 2010

Accepted: 10 Aug. 2010

Published: 24 Nov. 2010

How to cite this article: Horak, I.G., Heyne, H. \& Donkin, E.F., 2010, 'Parasites of domestic and wild animals in South Africa. XLVIII. Ticks (Acari: Ixodidae) infesting domestic cats and wild felids in southern Africa', Onderstepoort Journal of Veterinary Research 77(1), Art. \#3, 7 pages. DOI: 10.4102/ojvr.v77i1.3

\section{This article is available} at: http://www.ojvr.org

(C) 2010. The Authors. Licensee: OpenJournals Publishing. This work is licensed under the Creative Commons Attribution License.

\section{ABSTRACT}

Ticks collected from domestic cats (Felis catus), cheetahs (Acinonyx jubatus), caracals (Caracal caracal), African wild cats (Felis lybica), black-footed cats (Felis nigripes), a serval (Leptailurus serval), lions (Panthera leo), and leopards (Panthera pardus) were identified and counted. Thirteen species of ixodid ticks and one argasid tick were identified from domestic cats and 17 species of ixodid ticks from wild felids. The domestic cats and wild felids harboured 11 ixodid species in common. The adults of Haemaphysalis elliptica, the most abundant tick species infesting cats and wild felids, were most numerous on a domestic cat in late winter and in mid-summer, during 2 consecutive years. The recorded geographic distribution of the recently described Haemaphysalis colesbergensis, a parasite of cats and caracals, was extended by 2 new locality records in the Northern Cape Province, South Africa.

\section{INTRODUCTION}

Although several surveys on the ticks infesting domestic dogs in southern Africa have been conducted, little has been done about collecting ticks from domestic cats (Felis catus). The only reported surveys of ticks on domestic cats are those of Horak \& Matthee (2003), who identified ticks in 20 collections from cats presented at a private veterinary practice in Stellenbosch, Western Cape Province, Apanaskevich \& Horak (2008), who identified ticks collected from 4 cats at Colesberg in the Eastern Cape Province and a single cat at Prince Albert in the Western Cape Province, and Horak et al. (2000), who collected ticks from 7 feral cats in the Kruger National Park. Horak \& Matthee (2003) recorded 5 ixodid tick species from cats at Stellenbosch, Apanaskevich \& Horak (2008) described a new species, Haemapysalis colesbergensis, from the collections which they had examined, and Horak et al. (2000) recovered 7 ixodid tick species from feral cats in the Kruger National Park.

Considerably more time has been devoted to the ticks infesting wild felids than to those on domestic cats. Horak et al. $(1987 \mathrm{c} ; 2000)$ examined collections from 6 wild felid species, of which caracals (Caracal caracal) and lions (Panthera leo) accounted for the majority. They recorded 22 ixodid tick species from the 90 felids that were examined.

Since the late 1970s and early 1980s, Horak and Heyne have identified ticks in chance collections made by themselves and others from domestic cats and from wild felids. Furthermore, Donkin has collected ticks regularly from his family cat over a period of 26 consecutive months. This paper documents our findings on the identities and numbers of ticks collected from domestic cats and from wild felids in southern Africa.

\section{MATERIALS AND METHODS}

Ticks were collected from 130 domestic cats (Felis catus), 23 cheetahs (Acinonyx jubatus), 21 caracals, 3 African wild cats (Felis lybica), 5 black-footed cats (Felis nigripes), a single serval, Leptailurus serval, 9 lions and 8 leopards (Panthera pardus). The collections from domestic cats, caracals, African wild cats, blackfooted cats and the serval were all made in South Africa. Those from cheetahs were undertaken in South Africa and Namibia, while the collections from lions and leopards were carried out in South Africa, Namibia and Botswana. The ticks were gathered from domestic cats by their owners or by us, and we have construed the 26 consecutive monthly collections from Donkin's cat as though they were taken from 26 separate cats. Ticks were taken from wild felids by veterinarians, animal health technicians, or researchers, while the animals were immobilised for translocation or other purposes; however, complete collections were rarely possible. The species of animal which were host to the ticks, the date and the locality of the collection were recorded. If ticks were not immediately stored in $70 \%$ ethanol in glass or plastic vials until assessment, they were transferred to this medium as soon as they had been examined.

The Donkin family cat appeared to be a dominant male that roamed freely around the surrounding properties in the 'Die Wilgers' suburb of eastern Pretoria, Gauteng Province, South Africa. From June 2004 to July 2006, all visible ticks were taken from this cat at weekly intervals or less. The ticks collected during each month were pooled and separately preserved as described, until they were identified and counted, and their numbers used to determine the seasonal abundance of adult Haemaphysalis elliptica.

\section{RESULTS}

The numbers and species of ticks collected from domestic cats, the number of cats infested with each species and the province in which a particular tick species was collected are summarised in Table 1. A total of 13 ixodid tick species and 1 argasid species were recovered from the domestic cats, and of these, $H$. elliptica, followed by $H$. colesbergensis were the most predominant. The ticks taken from various wild felids, and the province or country in which they were collected, are summarised in Tables 2-6. Of the 17 ixodid tick species recovered from wild felids, H. elliptica was again the most numerous. Eleven ixodid tick species were common to the domestic cats and wild felids. 
TABLE 1

Ticks collected from 130 domestic cats in five of South Africa's nine provinces

\begin{tabular}{|c|c|c|c|c|c|c|}
\hline \multirow[t]{2}{*}{ Tick species } & \multicolumn{4}{|c|}{ Number of ticks collected } & \multirow[t]{2}{*}{ Number of cats infested } & \multirow[t]{2}{*}{ Province } \\
\hline & Nymphs & Males & Females & Total & & \\
\hline Amblyomma hebraeum & 16 & 0 & 0 & 16 & 2 & GP, EC \\
\hline Haemaphysalis colesbergensis & 0 & 22 & 50 & 72 & 8 & NC \\
\hline Haemaphysalis elliptica* & 13 & 840 & 945 & 1798 & 92 & GP, WC, EC, NC \\
\hline Haemaphysalis zumpti & 0 & 0 & 1 & 1 & 1 & WC \\
\hline Ixodes spp. & 110 & 1 & 6 & 117 & 24 & $\mathrm{EC}, \mathrm{WC}, \mathrm{GP}, \mathrm{KZN}$ \\
\hline Ixodes corwini & $?$ & 3 & 9 & 12 & 5 & $E C, W C$ \\
\hline Ixodes myotomys & $?$ & 0 & 1 & 1 & 1 & GP \\
\hline Ixodes pilosus & $?$ & 0 & 4 & 4 & 2 & EC \\
\hline Ixodes rubicundus & 0 & 0 & 5 & 5 & 2 & NC \\
\hline Rhipicentor nuttalli & 0 & 0 & 1 & 1 & 1 & GP \\
\hline Rhipicephalus gertrudae & 0 & 6 & 6 & 12 & 5 & WC, EC \\
\hline Rhipicephalus simus & 0 & 5 & 3 & 8 & 4 & EC, GP, WC \\
\hline Rhipicephalus turanicus & 0 & 6 & 4 & 10 & 2 & GP \\
\hline Rhipicephalus zambeziensis & 0 & 0 & 1 & 1 & 1 & GP \\
\hline Otobius megnini & 41 & 0 & 0 & 41 & 2 & GP \\
\hline
\end{tabular}

GP, Gauteng Province; EC, Eastern Cape Province; NC, Northern Cape Province; WC, Western Cape Province; KZN, KwaZulu-Natal Province

$?,=$ nymphs of these species possibly included amongst those of Ixodes spp.

*, 27 H. elliptica larvae

TABLE 2

Ticks collected from 23 cheetahs in South Africa and Namibia

\begin{tabular}{|c|c|c|c|c|c|c|}
\hline \multirow[t]{2}{*}{ Tick species } & \multicolumn{4}{|c|}{ Number of ticks collected } & \multirow[t]{2}{*}{ Number of cheetahs infested } & \multirow[t]{2}{*}{ Province or country } \\
\hline & Nymphs & Males & Females & Total & & \\
\hline Amblyomma hebraeum & 0 & 4 & 4 & 8 & 1 & LP \\
\hline Haemaphysalis elliptica & 5 & 38 & 76 & 119 & 12 & LP, GP, FS \\
\hline Rhipicentor bicornis & 0 & 19 & 2 & 21 & 10 & Namibia \\
\hline Rhipicentor nuttalli & 0 & 29 & 12 & 41 & 5 & GP \\
\hline Rhipicephalus gertrudae & 0 & 1 & 0 & 1 & 1 & Namibia \\
\hline Rhipicephalus simus & 0 & 2 & 0 & 2 & 1 & Namibia \\
\hline
\end{tabular}

GP, Gauteng Province; LP, Limpopo Province; FS, Free State Province.

TABLE 3

Ticks collected from 21 caracals in the Eastern Cape, Western Cape and Northern Cape Provinces, South Africa

\begin{tabular}{|c|c|c|c|c|c|c|}
\hline \multirow[t]{2}{*}{ Tick species } & \multicolumn{4}{|c|}{ Number of ticks collected } & \multirow[t]{2}{*}{ Number of caracals infested } & \multirow[t]{2}{*}{ Province } \\
\hline & Nymphs & Males & Females & Total & & \\
\hline Amblyomma marmoreum & (1 larva) & 0 & 0 & 1 & 1 & EC \\
\hline Haemaphysalis colesbergensis & 0 & 22 & 8 & 30 & 5 & NC \\
\hline Haemaphysalis elliptica & 0 & 28 & 3 & 31 & 7 & WC \\
\hline Haemaphysalis zumpti & 0 & 10 & 12 & 22 & 6 & NC, WC \\
\hline Ixodes pilosus gr. & 0 & 3 & 3 & 6 & 2 & WC \\
\hline Ixodes rubicundus & 0 & 13 & 24 & 37 & 8 & WC, NC \\
\hline Ixodes spp. & 2 & 0 & 1 & 3 & 2 & WC \\
\hline Rhipicentor bicornis & 0 & 1 & 0 & 1 & 1 & NC \\
\hline Rhipicentor nuttalli & 0 & 1 & 2 & 3 & 2 & NC \\
\hline Rhipicephalus evertsi evertsi & 1 & 0 & 0 & 1 & 1 & WC \\
\hline Rhipicephalus gertrudae & 0 & 0 & 5 & 5 & 3 & wC \\
\hline
\end{tabular}

EC, Eastern Province; NC, Northern Cape Province; WC, Western Cape Province.

TABLE 4

Ticks collected from 3 African wild cats, 5 black-footed cats and a serval in four of South Africa's nine provinces

\begin{tabular}{|c|c|c|c|c|c|}
\hline \multirow[t]{2}{*}{ Tick species } & \multicolumn{3}{|c|}{ Number of ticks collected } & \multirow[t]{2}{*}{ Number of cats infested } & \multirow[t]{2}{*}{ Province } \\
\hline & Males & Females & Total & & \\
\hline \multicolumn{6}{|l|}{ African wild cats (3) } \\
\hline Haemaphysalis colesbergensis & 5 & 11 & 16 & 2 & $\mathrm{EC}, \mathrm{NC}$ \\
\hline Ixodes rubicundus & 3 & 4 & 7 & 2 & $E C, W C$ \\
\hline \multicolumn{6}{|l|}{ Black-footed cats (5) } \\
\hline Haemaphysalis zumpti & 11 & 5 & 16 & 5 & NC \\
\hline Heamaphysalis spp. & 3 & 1 & 4 & 2 & NC \\
\hline \multicolumn{6}{|l|}{ Serval (1) } \\
\hline Haemaphysalis spinulosa & 7 & 3 & 10 & 1 & GP \\
\hline
\end{tabular}

EC, Eastern Cape Province; NC, Northern Cape Province; WC, Western Cape Province. 
TABLE 5

Ticks collected from 9 lions in South Africa, Botswana and Namibia

\begin{tabular}{|c|c|c|c|c|c|c|}
\hline \multirow[t]{2}{*}{ Tick species } & \multicolumn{4}{|c|}{ Number of ticks collected } & \multirow[t]{2}{*}{ Number of lions infested } & \multirow[t]{2}{*}{ Province or country } \\
\hline & Nymphs & Males & Females & Total & & \\
\hline Amblyomma hebraeum & 0 & 4 & 0 & 4 & 1 & LP \\
\hline Haemaphysalis elliptica & 7 & 19 & 27 & 53 & 3 & MP, FS \\
\hline Hyalomma truncatum & 0 & 11 & 5 & 16 & 3 & NC, Botswana, Namibia \\
\hline Rhipicentor bicornis & 0 & 1 & 0 & 1 & 1 & Namibia \\
\hline Rhipicephalus simus & 0 & 1 & 3 & 4 & 1 & LP \\
\hline Rhipicephalus turanicus & 0 & 2 & 1 & 3 & 2 & Namibia \\
\hline
\end{tabular}

LP, Limpopo Province; MP, Mpumalanga Province; FS, Free State Province; NC, Northern Cape Province.

TABLE 6

Ticks collected from 8 leopards in South Africa, Botswana and Namibia

\begin{tabular}{|c|c|c|c|c|c|c|}
\hline \multirow[t]{2}{*}{ Tick species } & \multicolumn{4}{|c|}{ Number of ticks collected } & \multirow[t]{2}{*}{ Number of leopards infested } & \multirow[t]{2}{*}{ Province or country } \\
\hline & Nymphs & Males & Females & Total & & \\
\hline Amblyomma hebraeum & 1 & 0 & 0 & 1 & 1 & Botswana \\
\hline Haemaphysalis elliptica & 0 & 56 & 2 & 58 & 4 & MP, WC \\
\hline Rhipicentor bicornis & 0 & 6 & 3 & 9 & 1 & Namibia \\
\hline Rhipicentor nuttalli & 0 & 7 & 0 & 7 & 1 & MP \\
\hline Rhipicephalus capensis & 0 & 0 & 1 & 1 & 1 & WC \\
\hline Rhipicephalus evertsi evertsi & 0 & 0 & 2 & 2 & 1 & Botswana \\
\hline Rhipicephalus zambesiensis & 0 & 8 & 3 & 11 & 1 & Botswana \\
\hline
\end{tabular}

\section{DISCUSSION}

\section{Amblyomma hebraeum}

Adult Amblyomma hebraeum are parasites of very large herbivores such as domestic cattle, African buffaloes (Syncerus caffer), elands (Taurotragus oryx), giraffes (Giraffa camelopardalis), and white and black rhinoceroses (Ceratotherium simum and Diceros bicornis) (Norval 1983; Horak et al. 1987b; Walker 1991; Horak, Golezardy \& Uys 2007). The immature stages, particularly the larvae, attach to the same hosts as the adult ticks, as well as small domestic ruminants, a large variety of smaller wild ruminants, domestic and wild carnivores, scrub hares (Lepus saxatilis), ground-frequenting birds and leopard tortoises (Geochelone pardalis) (Horak et al. 1987b, 2000, 2007; Dower, Petney \& Horak 1988; Horak, Emslie \& Spickett 2001). It is thus not surprising that two of the cats and a leopard were infested with immature ticks, while a single cheetah and a lion harboured a few adult ticks.

\section{Amblyomma marmoreum}

The adults and nymphs of Amblyomma marmoreum are parasites particularly of leopard tortoises (Horak et al. 2006), whereas the larvae will infest leopard tortoises and the same hosts as those listed above for the larvae of A. hebraeum (Horak et al. 1987b, 2006). Wild felids feature prominently amongst these host species, with collections recorded from feral cats, cheetahs, caracals, lions and leopards (Horak et al. 1987c, 2000).

\section{Haemaphysalis colesbergensis}

This tick has been described only recently in collections made from domestic cats in the Northern Cape and Western Cape Provinces (Apanaskevich \& Horak 2008). It had already been recorded on caracals in the Eastern Cape Province during 1984 and 1985, but at the time was incorrectly identified as Haemaphysalis leachi (Horak et al. 1987c). Upon re-examination, the species proved to be $H$. colesbergensis.

The preference of $H$. colesbergensis for domestic cats and caracals as hosts is now confirmed by the collections reported here. This tick species harvested from domestic cats at Fraserburg and Calvinia, in the Northern Cape Province, indicates new locality records. Taken in conjunction with previous records (Apanaskevich \& Horak 2008), the species is present in the Northern Cape, Eastern Cape and Western Cape Provinces in regions with a semi-arid to arid climate.

\section{Haemaphysalis elliptica}

In South Africa and parts of southern Africa, this species was known as $H$. leachi, with which it had previously been synonymised. However, Apanaskevich, Horak \& Camicas (2007) resurrected the name H. elliptica, and proved that it was a valid old southern African taxon. Furthermore, they showed that $H$. leachi sensu stricto is a separate taxon, which is present further north in Africa, and after re-examination of many of the specimens from earlier surveys in South Africa, came to the conclusion that all of those identified as $H$. leachi were, in fact, H. elliptica.

H. elliptica is a three-host species of which the larvae and nymphs use murid rodents as hosts (Norval 1984; Matthee et al. 2007) and are only exceptionally encountered on the same carnivore hosts as the adults (Apanaskevich et al. 2007). It is one of the major species that was collected from domestic dogs in two surveys conducted in Mozambique (Neves, Afonso \& Horak 2004; De Matos, et al. 2008), and in several surveys conducted on dogs in South Africa (Horak et al. 1987c, 2001; Horak 1995; Jacobs et al. 2001; Horak \& Matthee 2003; Nyangiwe, Horak \& Bryson 2006). It was also the most abundant and prevalent tick on domestic cats in a study conducted in the Western Cape province (Horak \& Matthee 2003). Furthermore, large numbers have been collected from the three largest wild cats in South Africa, namely cheetahs, lions and leopards (Horak et al. 1987c, 2000). With the exception of the survey carried out by De Matos et al. (2008), in which the name H. elliptica was used for this tick, all of these surveys refer to this species as H. leachi.

The relatively large number of domestic cats now recorded as infested, and the large numbers of ticks regularly collected from the Donkin family cat, establish $H$. elliptica as a major parasite of these animals. It is the vector of Babesia rossi in dogs (Lewis et al. 1996 [then referred to as H. leachi]), but whether it also transmits Babesia felis to cats remains to be demonstrated.

Seasonal fluctuations in the monthly numbers of adult $H$. elliptica harvested from the family cat are illustrated graphically in Figure 1. Although deducing the seasonality of a tick species from collections taken from a single host animal is decidedly risky, the fact that the collections were made over a period of 2 years and resulted in a reasonably similar annual pattern, somewhat underpins the results obtained by this approach. The number of ticks recovered monthly from the cat increased erratically from the commencement of the survey in June 2004, 


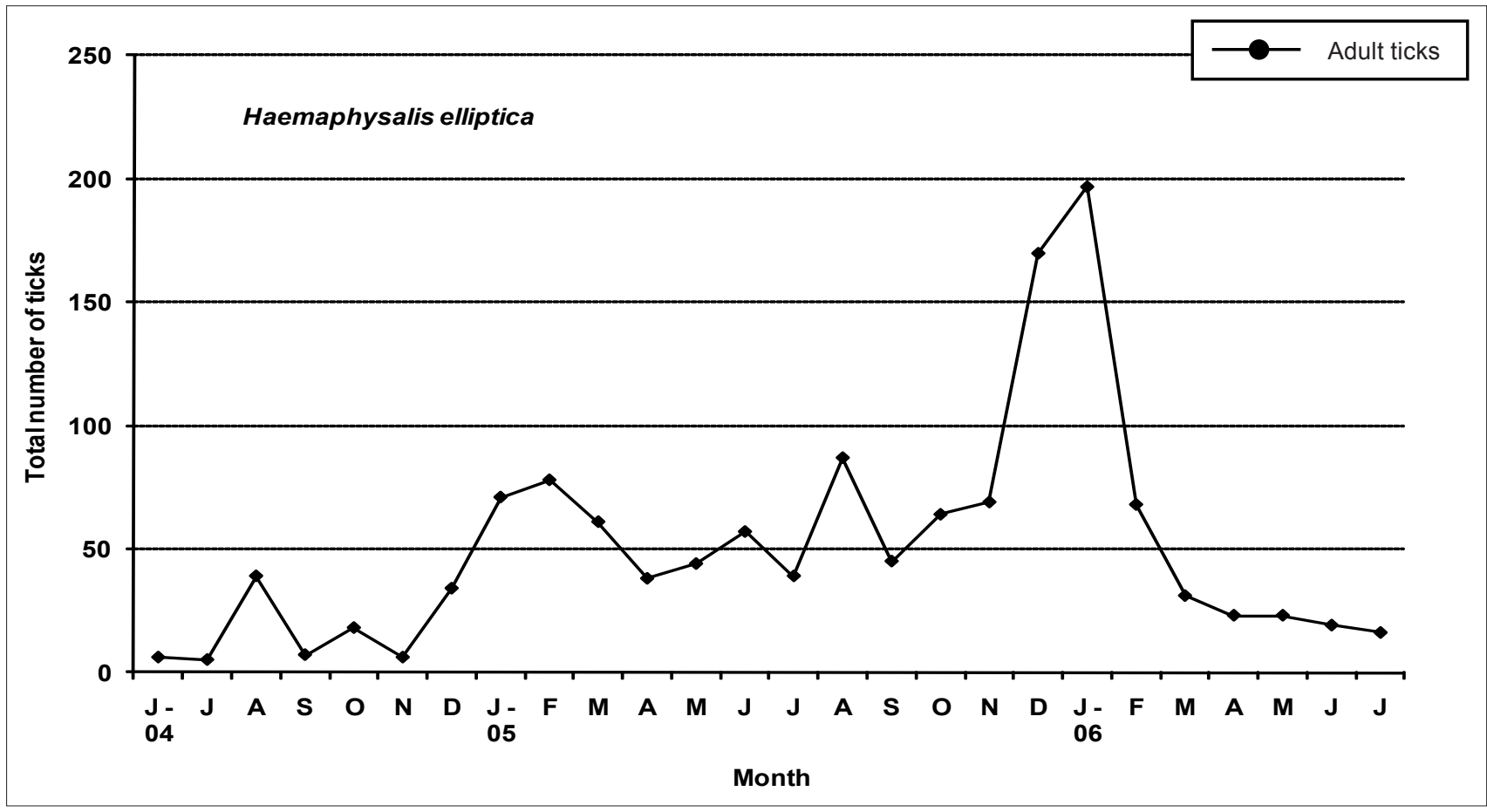

FIGURE 1

Total numbers of adult Haemaphysalis elliptica collected each month, from June 2004 to July 2006, from a male domestic cat in the eastern suburbs of Pretoria, Gauteng Province, South Africa

reaching a peak during January 2006. Within this increasing pattern of infestation, tick numbers reached minor peaks in August 2004 and 2005 (late winter), with major peaks during the mid-summer months of January and February 2005, and December 2005 and January 2006. Despite the smaller numbers of adult ticks present in late summer and winter, their presence during these seasons indicates that the life cycle of H. elliptica continues throughout the year in Pretoria. This pattern of seasonality is similar to that on domestic dogs belonging to people in rural communities in north-eastern KwaZulu-Natal Province, South Africa (Horak et al. 2001)

Only 13 nymphs were recovered along with the total of 1785 adult $H$. elliptica collected from the cats, and 12 nymphs from the wild felids, indicating that these animals alone would not be able to maintain this species. It also implies that there must have been an abundance of murid rodents in the vicinity to serve as hosts for the immature stages of the tick (Braack et al. 1996).

\section{Haemaphysalis zumpti}

According to Walker (1991), the adults of Haemaphysalis zumpti are parasites of small carnivores. The presence of $\mathrm{H}$. zumpti on a single domestic cat, 5 black-footed cats and 6 caracals, while none were collected from cheetahs, lions and leopards, confirms this observation.

\section{Hyalomma truncatum}

Adults of Hyalomma truncatum prefer domestic cattle and large, wild bovids as hosts (Norval 1982; Horak et al. 2007), but a single tick has been collected from an African wild cat and 4 from a lion in Zimbabwe (Norval 1982), while in South Africa single ticks have also been taken from a cheetah and two lions (Horak et al. 2000). The 3 infested lions were all examined within the core distribution range of this tick in southern Africa (Theiler 1962; Walker 1991).

\section{Ixodes corwini}

The original description of Ixodes corwini by Keirans, Clifford, \& Walker (1982) is based on a tick collected from a Cape clawless otter (Aonyx capensis) in the Western Cape Province, and it was also recorded by them as present on mongooses and genets. Horak et al. (1987c) recovered I. corwini from dogs on smallholdings near Grahamstown in the Eastern Cape Province, and we now report it as present on domestic cats in the same region, as well as from East London in the same province, and from Knysna in the Western Cape Province.

\section{Ixodes pilosus group}

There appear to be 3 possible species within this group (McKay 1994). Although ticks in this complex have a very wide host range, including domestic dogs, caracals, various antelopes and scrub hares (Horak et al. 1987c; Horak \& Boomker 1998) large numbers of adult ticks are seldom taken from a single host. The collection of ticks from 2 cats and 2 caracals in this study and from 7 cats in a survey by Horak \& Matthee (2003), confirms a partiality of this group for felids. Horak et al. (1987c) recorded adult ticks mainly from January to May on 22 caracals examined in the Eastern Cape Province.

\section{Ixodes rubicundus}

Although Stampa (1959), Theiler (1962), Horak, Moolman \& Fourie (1987a) and Walker (1991) all record caracals amongst a variety of other mammals as hosts of adult Ixodes rubicundus, none of them has mentioned its presence on domestic cats or dogs. Jacobs et al. (2001) report the occurrence of 7 ticks of this species on dogs and Horak \& Matthee (2003), who harvested ticks from dogs and cats, record the presence of 9 such ticks on dogs, but none on cats. The presence of I. rubicundus ticks on 2 domestic cats in our study suggests that they may be good hosts of this species, but that their usually owner-restricted home ranges preclude the likelihood of their becoming infested. Ticks of this species were collected from 2 of the 3 African wild cats examined and 8 of the 21 caracals. Stampa (1959) recovered ticks from both these felid species. The immature stages of I. rubicundus infest elephant shrews (Elephantulus spp.), and Smith's red rock rabbits (Pronolagus rupestris), and the adults infest sheep, goats and cattle, as well as various wild bovids (Stampa 1959; Horak et al. 1987a; Fourie, Kok \& Heyne 1996; Fourie, Horak \& Woodall 2005). Careful examination of caracals has, however, indicated that they are infested by all stages of development of this species (Horak et al. 1987a, 1987c), 
and that they can therefore most likely support the life cycle of the tick in the absence of all other host species.

\section{Other Ixodes species}

A single Ixodes myotomus female was collected from a domestic cat. This species normally infests bush Karoo rats (Otomys unisulcatus) (Walker 1991), and the cat may have become naturally infested, or it could have acquired infestation by eating a rat on which an unattached or loosely attached female tick was present. However, the geographic distribution of $O$. unisulcatus does not include the Pretoria district, where the tick was recovered, and we must therefore assume that other murid rodent species can also harbour I. myotomus. A relatively large number of Ixodes spp. nymphs, of which the largest proportion probably belonged to the Ixodes pilosus group, were recovered from domestic cats, and two were taken from caracals. A cat also harboured a single Ixodes sp. male, and cats and caracals Ixodes spp. females, which we were unable to identify.

\section{Rhipicentor bicornis}

The genus Rhipicentor contains only two species, and the distributions of both are restricted to Africa (Theiler 1961, 1962; Walker 1991). The hosts of the immature stages of Rhipicentor bicornis are unknown, but as in the case of Rhipicentor nuttalli, are likely to be rock elephant shrews (Elephantulus myurus). Theiler (1962) records adult $R$. bicornis on jackals, genets and several wild felids. In this study, 10 cheetahs, a lion and a leopard in Namibia, as well as a single caracal in the Northern Cape Province, South Africa, were infested with adult ticks.

\section{Rhipicentor nuttalli}

Fourie et al. (2002) have demonstrated that rock elephant shrews are the preferred hosts of the immature stages of this three-host tick. The adults target domestic dogs, hyaenas, lions, leopards, South African hedgehogs (Atelerix frontalis) and porcupines (Hystrix africaeaustralis) (Theiler 1962; Norval \& Colborne 1985; Walker 1991; Horak et al. 2000). In this study, a single domestic cat, 5 cheetahs, 2 caracals and a leopard were infested with adult ticks. Theiler (1962) mentions that the adults are common on domestic dogs in the Clanwilliam district of the Western Cape Province, South Africa, and in the Omaruru district, Namibia, during late summer. Infestation with adult ticks can lead to paralysis in dogs (Perchman 1976; Norval \& Colborne 1985).

\section{Rhipicephalus capensis}

The distribution of Rhipicephalus capensis is restricted to South Africa in a narrow zone along the western coast of the Western and Northern Cape Provinces, with a single occurrence recorded in the Eastern Cape Province (Walker, Keirans \& Horak 2000). We collected a single female tick from a leopard in the Western Cape Province in this study.

\section{Rhipicephalus gertrudae}

Rhipicephalus gertrudae is present only in South Africa and Namibia (Walker et al. 2000). It is a three-host tick and its adults feed on cattle, sheep, wild bovids and domestic and wild carnivores, while its immature stages prefer murid rodents (Walker et al. 2000; Matthee et al. 2007). Until 2000, only three adult $R$. gertrudae had been recorded on domestic dogs and none from cats (Walker et al. 2000). However, as soon as surveys were conducted within its distribution range, this situation changed. Jacobs et al. (2001) collected $R$. gertrudae from 7 dogs examined in central Free State Province, while Horak \& Matthee (2003) found 83 instances on dogs and 2 on domestic cats in the Western Cape Province. We now add a further 5 instances from cats, and 3 from caracals to the existing 3 records for caracals, as well as a cheetah in Namibia, as a new host record.

In the southern and north-western winter rainfall regions of South Africa, R. gertrudae is found predominantly on sheep and dogs during May to October (Horak \& Fourie 1992; Horak
\& Matthee 2003). In Namibia and in the semi-arid regions of the western central summer rainfall region of South Africa, it is most abundant on cattle from September or October, to February or March (Biggs \& Langenhoven 1984; Fourie, Kok \& Heyne 1996).

\section{Rhipicephalus sanguineus}

It may appear illogical to include a discussion on a tick species that was not even collected in this study, but the mere fact of its absence is significant. Rhipicephalus sanguineus and H. elliptica have been the most abundant tick species found on domestic dogs during the various surveys conducted on these animals in southern Africa (Goldsmid 1963; Horak 1995; Bryson et al. 2000; Jacobs et al. 2001; Horak \& Matthee, 2003; Neves et al. 2004; De Matos et al. 2008). However, not a single R. sanguineus was recovered from domestic cats or wild felids in our survey, or in that conducted on 23 species of wild carnivores by Horak et al. (2000), or that by Horak \& Matthee (2003) on domestic cats in the Western Cape Province. These findings serve as additional confirmation of the near-strict host preference of $R$. sanguineus for domestic dogs.

\section{Rhipicephalus simus}

Rhipicephalus simus replaces $R$. gertrudae in the more moist eastern regions of South Africa, and its immature and adult stages have the same host preferences as R. gertrudae (Walker et al. 2000). Although Walker et al. (2000) list only a single collection of $R$. simus from a domestic cat, they record several from wild felids. Horak et al. (2000) added 2 instances of $R$. simus on cheetahs, 17 on lions and 2 on leopards to this list, while this study adds 4 from domestic cats and 1 each from a cheetah and a lion.

\section{Rhipicephalus turanicus}

The identities of Rhipicephalus turanicus and R. sanguineus have been confused so frequently that numerous incorrect host records for $R$. sanguineus have been published. Both ticks occur on domestic dogs, sometimes even simultaneously (De Matos et al. 2008), but with extremely rare exceptions, it is $R$. turanicus, and not $R$. sanguineus that is recovered from hosts other than domestic dogs (Walker et al. 2000). The adults of $R$. turanicus have a very wide host range, including nearly all domestic animals, as well as wild canids, felids, suids, equids, bovids, leporids and even some of the larger species of birds (Walker $e t$ al. 2000). Walker et al. (2000) record 4 occurrences of $R$. turanicus on domestic cats and 35 on wild felids, to which we now add 2 from cats and 2 from lions.

\section{Other Rhipicephalus species}

The collection of a Rhipicephalus evertsi evertsi nymph from a caracal and its adults from a leopard should be viewed as accidental or opportunistic infestations, as this tick does not normally target felids (Walker et al. 2000). The stable cat from which an adult Rhipicephalus zambeziensis was recovered is likely to have acquired infestation from a stray tick during a study involving this tick species. $R$. zambezienis adults have been collected previously from cheetahs, lions and leopards (Horak et al. 2000; Walker et al. 2000).

\section{Otobius megnini}

The spinose ear tick, as this argasid tick species is known colloquially, is dependent for its survival on man-made structures and the micro-environment in its immediate vicinity. Hence its presence in the ears of cattle that are confined at night in stone kraals, calves reared in unplastered calf-pens constructed from bricks (Howell, Walker \& Nevill 1978; Fourie \& Horak 1990), stabled horses, people that ride or that are associated with horses (Naudé et al. 2001; Huchzermeyer 2002), or dogs and cats kept in the vicinity of infested premises. Some of the cats examined in this study were stable cats, and one of them harboured 40 Otobius megnini nymphs in its ears. 


\section{CONCLUSION}

Nineteen ixodid tick species were recovered from domestic cats and the seven species of wild felids that inhabit South Africa. The cats and wild felids are good hosts of only one tick species of veterinary importance, which is $H$. elliptica, the vector of $B$. rossi to domestic dogs.

\section{ACKNOWLEDGEMENTS}

The authors acknowledge with gratitude the collections of ticks made from domestic cats by Drs Maureen Baker, Jenny Randles, and the late Amy Jacot Guillarmod, from black-footed cats by Dr Nadine Lamberski, and from cheetahs and a leopard by Prof. H.J. Bertschinger. The study was funded by the University of Pretoria, the University of the Free State and the National Research Foundation.

\section{REFERENCES}

Apanaskevich, D.A., Horak, I.G. \& Camicas, J.-L., 2007 'Redescription of Haemaphysalis (Rhipistoma) elliptica (Koch, 1844), an old taxon of the Haemaphysalis (Rhipistoma) leachi group from East and southern Africa, and of Haemaphysalis (Rhipistoma) leachi (Audouin, 1826) (Ixodida, Ixodidae)', Onderstepoort Journal of Veterinary Research 74, 181-207.

Apanaskevich, D.A. \& Horak, I.G., 2008, 'Two new species of African Haemaphysalis ticks (Acari: Ixodidae), carnivore parasites of the H. (Rhipistoma) leachi group', Journal of Parasitology 94, 594-607.

Biggs, H.C. \& Langenhoven, J.W., 1984, 'Seasonal prevalence of ixodid ticks on cattle in the Windhoek District of South West Africa/Namibia', Onderstepoort Journal of Veterinary Research 51, 175-182.

Braack, L.E.O., Horak, I.G., Jordaan, L.C., Segerman, J. \& Louw, J.P., 1996, 'The comparative host status of red veld rats (Aethomys chrysophilus) and bushveld gerbils (Tatera leucogaster) for epifaunal arthropods in the southern Kruger National Park, South Africa', Onderstepoort Journal of Veterinary Research 63, 149-158.

Bryson, N.R., Horak, I.G., Höhn, E.W. \& Louw, J.P., 2000, 'Ectoparasites of dogs belonging to people in resource-poor communities in North West Province, South Africa', Journal of the South African Veterinary Association 71, 175-179.

De Matos, C., Sitoe, C., Neves, L., Bryson, N.R. \& Horak, I.G., 2008, 'Ixodid ticks on dogs belonging to people in rural communities and villages in Maputo Province, Mozambique', Onderstepoort Journal of Veterinary Research 75 103-108.

Dower, K.M., Petney, T.N. \&Horak, I.G., 1988, 'The developmental success of Amblyomma hebraeum and Amblyomma marmoreum on the leopard tortoise, Geochelone pardalis', Onderstepoort Journal of Veterinary Research 55, 11-13.

Fourie, L.J. \& Horak, I.G., 1990, 'Parasites of cattle in the southwestern Orange Free State', Journal of the South African Veterinary Association 61, 27-28.

Fourie, L.J., Kok, D.J. \& Heyne, H., 1996 'Adult ixodid ticks on two cattle breeds in the south-western Free State, and their seasonal dynamics', Onderstepoort Journal of Veterinary Research 63, 19-23.

Fourie, L.J., Horak, I.G., Kok, D.J. \& Van Zyl, W., 2002, 'Hosts, seasonal occurrence and life cycle of Rhipicentor nuttalli (Acari: Ixodidae)', Onderstepoort Journal of Veterinary Research 69, 177-187.

Fourie, L.J., Horak, I.G. \& Woodall, P.F., 2005, 'Elephant shrews as hosts of immature ixodid ticks', Onderstepoort Journal of Veterinary Research 72, 293-301.

Goldsmid, J.M., 1963, 'Ticks infesting dogs in the Salisbury area of Southern Rhodesia', Journal of the South African Veterinary Medical Association 34, 609-610.

Horak, I.G., 1995, 'Ixodid ticks collected at the Faculty of Veterinary Science, Onderstepoort, from dogs diagnosed with Babesia canis infection', Journal of the South African Veterinary Association 66, 170-171.
Horak, I.G., Moolman, L.C. \& Fourie, L.J., 1987a, 'Some wild hosts of the Karoo paralysis tick, Ixodes rubicundus Neumann, 1904 (Acari: Ixodidae)', Onderstepoort Journal of Veterinary Research 54, 49-51.

Horak, I.G., MacIvor, K.M. De F., Petney, T.N. \& De Vos, V., 1987b, 'Some avian and mammalian hosts of Amblyomma hebraeum and Amblyomma marmoreum (Acari: Ixodidae)', Onderstepoort Journal of Veterinary Research 54, 397-403.

Horak, I.G., Jacot Guillarmod, A., Moolman, L.C. \& De Vos, V., 1987c, 'Parasites of domestic and wild animals in South Africa. XXII. Ixodid ticks on domestic dogs and on wild carnivores', Onderstepoort Journal of Veterinary Research 54, 573-580.

Horak, I.G. \& Fourie, L.J., 1992, 'Parasites of domestic and wild animals in South Africa. XXXI. Adult ixodid ticks on sheep in the Cape Province and in the Orange Free State', Onderstepoort Journal of Veterinary Research 59, 275-283.

Horak, I.G. \& Boomker, J., 1998, 'Parasites of domestic and wild animals in South Africa. XXXV. Ixodid ticks and bot fly larvae in the Bontebok National Park', Onderstepoort Journal of Veterinary Research 65, 205-211.

Horak, I.G., Braack, L.E.O., Fourie, L.J. \& Walker, J.B., 2000 'Parasites of domestic and wild animals in South Africa. XXXVIII. Ixodid ticks collected from 23 wild carnivore species', Onderstepoort Journal of Veterinary Research 67, 239-250

Horak, I.G., Emslie, F.R. \& Spickett, A.M., 2001, 'Parasites of domestic and wild animals in South Africa. XL. Ticks on dogs belonging to people in rural communities and carnivore ticks on the vegetation', Onderstepoort Journal of Veterinary Research 68, 135-141.

Horak, I.G. \& Matthee, S., 2003, 'Parasites of domestic and wild animals in South Africa. XLIII. Ixodid ticks of domestic dogs and cats in the Western Cape Province', Onderstepoort Journal of Veterinary Research 70, 187-195.

Horak, I.G., McKay, I.J., Heyne, H. \& Spickett, A.M., 2006 'Hosts, seasonality and geographic distribution of the South African tortoise tick, Amblyomma marmoreum', Onderstepoort Journal of Veterinary Research 73, 13-25.

Horak, I.G., Golezardy, H. \& Uys, A.C., 2007, 'Ticks associated with the three largest wild ruminant species in southern Africa', Onderstepoort Journal of Veterinary Research 74, 231-242.

Howell, C.J., Walker, J.B. \& Nevill, E.M., 1978, 'Ticks, mites and insects infesting domestic animals in South Africa', Part 1, Descriptions and biology, Department of Agricultural Technical Services, Republic of South Africa, Science Bulletin, No. 393, 69 pp.

Huchzermeyer, H.F., 2002, 'Another human ear tick case', Journal of the South African Veterinary Association 72:2.

Jacobs, P.A.H., Fourie, L.J., Kok, D.J. \& Horak, I.G., 2001, 'Diversity, seasonality and sites of attachment of adult ixodid ticks on dogs in the central region of the Free State Province, South Africa', Onderstepoort Journal of Veterinary Research 68, 281-290.

Keirans, J.E., Clifford, C.M. \& Walker, J.B., 1982, 'The Ixodes (Afrixodes) oldi group (Acari: Ixodidae) from sub-Saharan Africa with descriptions of five new species', Journal of Medical Entomology 19, 309-329.

Lewis, B.D., Penzhorn, B.L., Lopez-Rebollar, L.M. \& De Waal, D.T., 1996, 'Isolation of a South African vector-specific strain of Babesia canis', Veterinary Parasitology 63, 9-16.

Matthee, S., Horak, I.G., Beaucournu, J-C., Durden, L.A., Ueckermann, E.A. \& McGeoch, M.A., 2007, 'Epifaunistic arthropod parasites of the four-striped mouse, Rhabdomys pumilio, in the Western Cape Province, South Africa', Journal of Parasitology 93, 47-59.

McKay, I.J., 1994, 'Two new species of ixodid ticks closely related to Ixodes pilosus (Acari: Ixodidae)', Journal of the South African Veterinary Association 65, 158.

Naudé, T.W., Heyne, H., Van der Merwe, I.R. \& Benic, M.J., 2001, 'Spinose ear tick, Otobius megnini (Dugès, 1884) as the cause of an incident of painful otitis externa in humans', Journal of the South African Veterinary Association 72, 118-119. 
Neves, L., Afonso, S. \& Horak, I.G., 2004, 'Ixodid ticks on dogs in and around Maputo and elsewhere in Mozambique', Onderstepoort Journal of Veterinary Research 71, 279-283.

Norval, R.A.I., 1982, 'The ticks of Zimbabwe. IV. The genus Hyalomma', Zimbabwe Veterinary Journal 13, 2-10.

Norval, R.A.I., 1983, 'The ticks of Zimbabwe. VII. The genus Amblyomma' Zimbabwe Veterinary Journal 14, 3-18.

Norval, R.A.I., 1984, 'The ticks of Zimbabwe. IX. Haemaphysalis leachi and Haemaphysalis spinulosa', Zimbabwe Veterinary Journal, 15, 9-17.

Norval, R.A.I. \& Colborne, J., 1985, 'The ticks of Zimbabwe. $X$. The genera Dermacentor and Rhipicentor', Zimbabwe Veterinary Journal 16, 1-4.

Nyangiwe, N., Horak, I.G. \& Bryson, N.R., 2006, 'Ixodid ticks on dogs in the eastern region of the Eastern Cape Province, South Africa', Onderstepoort Journal of Veterinary Research 73, 305-309.

Perchman, G.E., 1976, 'Rhipicentor infestation in the dog: a case report', Rhodesian Veterinary Journal 7, 15-16.
Stampa, S., 1959, 'Tick paralysis in the Karoo areas of South Africa', Onderstepoort Journal of Veterinary Research 28, 169-227 + 1 map.

Theiler, G., 1961, 'A contribution to the knowledge of African Ixodidae. The genus Rhipicentor', Revue de Zoologie et de Botanique Africaines 66, 297-308.

Theiler, G., 1962, 'The Ixodoidea Parasites of Vertebrates in Africa South of the Sahara (Ethiopian Region)', Project S 9958, Report to the Director of Veterinary Services, Onderstepoort. Mimeographed, $260 \mathrm{pp}$.

Walker, J.B., 1991, 'A review of the ixodid ticks (Acari, Ixodidae) occurring in southern Africa', Onderstepoort Journal of Veterinary Research 58, 81-105.

Walker, J.B., Keirans, J.E. \& Horak, I.G., 2000, 'The genus Rhipicephalus (Acari, Ixodidae): a guide to the brown ticks of the world', Cambridge University Press, Cambridge. 